\title{
A GP prescription for exercise: Scotland to the Sahara
}

Andy Murray (a different Andy Murray!), who recently completed his GP training year with us in Hawick, is about to undertake the challenge of his life so far ... running from the snow in Scotland to the sand dunes of the Moroccan Sahara and covering 2650 miles, the equivalent of 100 marathons, in 85 days with no days off. He starts in November and, if he is successful (and those who know him don't doubt that he will be), he will earn himself a place in the Guinness Book of Records.

Not exactly a slouch to date (he recently shattered the record for running the length of Hadrian's Wall by finishing the 84-mile stretch in 16 hours and 59 minutes, 3 hours faster than previous holder, and he has run marathons at the North Pole, in the Gobi Desert and, the world's highest, around Everest), this latest challenge is about raising money for the Yamaa Trust, dedicated to the amelioration of poverty in the South Gobi region of Mongolia. It aims, this year, to fund a school for the deaf, provide funding for medical care and essential services.

Patients and colleagues alike were fascinated by Andy's exploits. Those who clearly subscribed to the definition of exercise as 'The art of converting big meals and fattening snacks into back strains and pulled muscles by lifting heavy things that don't need to be moved or running when noone is chasing you', (quoted in a talk, 'Physical Activity and Health', given by Dr

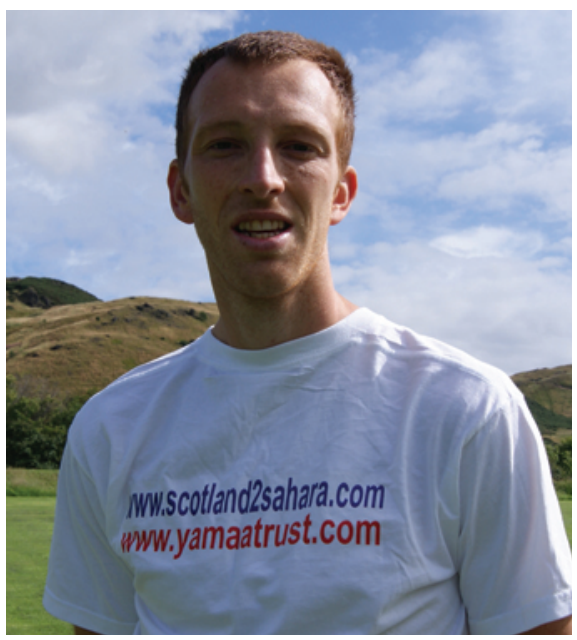

Roger Hawkes) may have struggled to empathise. Others who indulged in moderate exercise were also curious to know what motivated him. Why was he doing it?

\section{'As a GP I know that exercise is important to maintaining good health. A prescription for running 100 marathons in 85 days, from John $O$ Groats to the} Moroccan Sahara desert may seem excessive, but I hope it raises not just substantial amounts of money for the Yamaa Trust, but also interest in the benefits of a healthy lifestyle. During the scotland2sahara challenge I will need to eat approximately 6500 kcalories a day which, under normal circumstances, would lead to some fairly rampant weight gain, but fortunately l'll be expending this number of calories each day.

I will be the subject of a case study by a team from Coventry University, who will poke, prod, and obtain data from me. This will include assessing my physiology, body composition and how it changes, immune function, mood state, in conjunction with distance run, and calories used.

I will be joined for smaller sections by other doctors, including $\mathrm{Dr}$ Joe Symonds, who was recently 4th in the World Mountain Running Championships, Dr Jennie Reeves my long-suffering fiancee, and several of the doctors and staff from the Borders General Hospital and the Teviot Medical Practice.

I'm hoping to raise a stack of cash for the Yamaa Trust. I volunteer with them as a medical advisor, having spent time in Mongolia last year. Both they, and the other Mongolian people l've met are awesome, although the sour mare's milk tea is a delicacy lost on me.'

My most recent running challenge was not (I'm delighted to say) even one marathon but the Glasgow Womens' 10k. The one last May was the fourth one l'd done with my friend Annie. Last week, at work as a teacher, she developed a sudden, searing headache, was taken to the Western General in Edinburgh, operated on for her cerebral aneurysm and died a week later. Passionate about education, she had spent her life encouraging young people to achieve their potential. She had never met Andy; like most of us, she had no personal connection with Mongolia, but she would have thoroughly approved of what he is doing.

\section{Lesley Morrison}

You can follow Andy's adventure on his website, www.scotland2sahara.com or via the scotland2sahara facebook site, or @scotland2sahara on twitter.

If you would like to support Andy and the Yamaa Trust you can make a donation at www.justgiving.com/scotland2sahara. 